\title{
Prematüre Yenidoğanlarda Pulmoner Kanama Risk Faktörleri
}

\author{
Risk Factors of Pulmonary Hemorrhage in Preterm Infants \\ Elif Özalkaya, Hande Özgün Karatepe, Sevilay Topçuoğlu \\ Emre Dinçer, Güner Karatekin, Fahri Ovalı
}

Zeynep Kamil Kadın ve Çocuk Hastalıkları Eğitim ve Araştırma Hastanesi, Neonatoloji Kliniği, İstanbul, Türkiye

\section{ÖZET} Amaç: Prematürelerde pulmoner kanama siklı̆̆l ve
risk faktörlerini saptamaktır.

Gereç ve Yöntem: Bu çalışmada Ocak 2012 ile Ocak 2015 arasında yenidoğan yoğun bakım servisimize yatırlan 28 gestasyonel hafta altında pulmoner kanama kriterlerini karşllayan 37 olgu retrospektif olarak değerlendirilmiştir. Doğum a ăırlı̆̆ ve doğum haftası çalıșma grubuna benzer olan ve pulmoner kanamast olmayan 233 prematüre yenidoğan kontrol grubu olarak çalıșmaya alınmıştır. Antenatal ve postnatal tıbbi kayttlar geriye dönük değerlendirilmiştir.

Bulgular: Pulmoner kanamasi olan prematüreler ile kontrol grubu arasinda cinsiyet, sezaryen ile doğum, doğum odasında entübasyon, çoğul gebelik, preeklempsi, erken membran rüptürü, antenatal steroid, patent duktus arteriorus ve erken sepsis siklı̆̆l için farklılık saptanmamıştır. Pulmoner kanaması olan prematürelerde, kontrol grubuna göre pulmoner kanama öncesinde respiratuar distres sendromu (RDS) ve bu nedenle surfaktan verilme sikllğg yüksek saptanmuşıtır $(p<0,05)$.

Sonuç: Artan pulmoner kanama riskinden RDS mi yoksa surfaktan tedavisinin mi sorumlu olduğu ortaya konulamamiştır. Surfaktan ve pulmoner hemoroji arasindaki ilişkiyi ortaya koyan çalışmalara ihtiyaç vardır.

Anahtar Kelimeler: prematüre, pulmoner kanama, surfaktan

\section{ABSTRACT}

Objective: To determine the frequency and the risk factors of pulmonary hemorrhage in preterm infants.

Material and Method: In this study 37 preterm infants hospitalized between January 2012 to January 2015 with the diagnosis of pulmonary hemorrhage and less than 28 gestational weeks were evaluated retrospectively. 233 preterm infants whose birth weight and gestational week are similar to study group and without pulmonary hemorrhage are taken as control group. Antenatal and postnatal medical records evaluated retrospectively.

Results: No difference have been showed between study groups for gender, cesarean delivery, multiple pregnancies, intubation in delivery room, preeclampsia, premature rupture of membranes, maternal use of corticosteroids, patent ductus arteriosus and early onset sepsis. Newborns who had pulmonary hemorrhage had respiratory distress syndrome and received surfactants more frequently than the control group.

Conclusion: In this study whether the increasing risk factor of pulmonary hemorrhage is because of $R D S$ or treatment of surfactant has not been revealed. There needs more study to reveal the relationship between pulmonary hemorrhage and surfactant treatment.

Keywords: premature, hemorrhage, surfactant

\footnotetext{
İletişim Bilgileri:

Sorumlu Yazar: Elif ÖZALKAYA

Yazışma Adresi: Zeynep Kamil Kadın ve Çocuk Hast. Eğt. ve Araştırma Hastanesi, Neonatoloji Kliniği, İstanbul E-mail: elifozalkay@gmail.com

Makalenin Geliş Tarihi: 25.02.2015

Makalenin Kabul Tarihi: 23.06.2015

DOI: http://dx.doi.org/10.16948/zktb.38501
} 


\section{GİRİŞ}

Pulmoner kanama çok düşük doğum ağır11klı prematürelerde en yüksek mortalite nedenidir. Sıklığ 1 çok düşük doğum ağırlıklı prematürelerde $\% 3$ ile 32 arasında değişmektedir [1-4]. Pulmoner kanama risk faktörleri asfiksi, doğum odasında resusitasyon, eksik antenatal steroid $[5,6]$, düşük gestasyonel yaş ve hafta, patent duktus arteriorus (PDA), enfeksiyon ve surfaktan tedavisidir [7, 8]. Pulmoner kanama tedavisinde endotrakeal yol ile adrenalin ve yüksek frekanslı ventilasyon uygulanmaktadır [9]. Pulmoner kanama sonrasi ortamdaki hemoglobin, lipit ve protein surfaktan yetersizliğine neden olarak yüzey gerilimini arttırmakta ve ikincil respiratuar distres sendromu (RDS) gelişmektedir [10]. Pulmoner kanama sonras1 ikincil RDS'nin geliştiği durumlarda surfaktan uygulanabilir. Surfaktan tedavisinin pulmoner kanamayı arttırıp arttırmadığı tartışmalı olsa da, pulmoner kanama sonrasında gelişen RDS'de tedavi seçeneğidir [9]. Pulmoner kanama prematürelerde $\% 50$ ile 82 arasinda mortaliteye sahiptir [11-14]. Prematürenin yüksek mortalitesine neden olan pulmoner kanama ve risk faktörlerini değerlendiren az sayıda çalışma yapılmıștır. Bu çalıșmadaki amaç yenidoğan yoğun bakım servisine 3 yıl boyunca yatırılan 28 hafta altındaki prematürelerde pulmoner kanama sıklığını ve pulmoner kanama öncesinde pulmoner kanama için risk yaratan risk faktörlerini belirlemektir.

\section{GEREÇ ve YÖNTEM}

Zeynep Kamil Kadın Doğum ve Çocuk Hastalıkları Eğitim ve Araştırma Hastanesi Yenidoğan Yoğun Bakım Servisine Ocak 2012 ile Aralık 2014 yılları arasında yatırılan, 28. gestasyonel haftanın altındaki pulmoner kanaması olan 37 prematüre çalışma grubunu oluşturdu. Pulmoner kanaması olmayan, çalışma grubu ile benzer doğum ağırlığı ve doğum haftasına sahip 233 prematüre kontrol grubuna alınd1. Pulmoner kanama endotrakeal tüpdeki kanlı aspiratın görülmesinin ardından akciğer grafisinde multilobular infiltrasyonun görülmesi, artan ventilatör desteği ( $\mathrm{FiO}_{2}$ 'nin \%30 artmasi) veya hematokritte $\% 10$ 'dan fazla düşme olarak tanımlandı. Pulmoner kanama olan olgulara 0,5 cc epinefrin (1/1000) endotrakeal yol ile pulmoner kanama duruncaya kadar verildi. Endotrakeal aspirasyon sadece hipoksi ve dispne durumunda uyguland. Solunum yetmezliğinin devam ettiği durumlarda $\left(\mathrm{FiO}_{>}>\% 60\right.$ ve MAP $>12 \mathrm{cmH}_{2} \mathrm{O}$ ve/veya ph 7,25 altında ise) hasta HFO (yüksek frekanslı ossilasyon) ile ventile edildi. İkincil RDS pulmoner kanamadan sonra artan solunum sikıntısı semptomları ve akciğer grafisinde beyaz akciğer görünüm olması olarak tanımlandı. İkincil RDS'si olan olgulara surfaktan verildi. Olguların antenatal bulguları [cinsiyet, 5. dakika Apgar, çoğul gebelik, sezeryan doğum, erken membran rüptürü (doğumdan 24 saat öncesinde amniotik zarların yırtılmas1), korioamnionit [9, 10], oligohidroamnioz (amnion mai indeksinin $5 \mathrm{~cm}$ 'den az olmasi), preeklampsi [11], antenatal steroid [12] ve postnatal bulguları [doğumdan sonra pulmoner kanamadan önce gelişen RDS [12], surfaktan tedavisi, PDA (ekokardiyografide patent duktus arteriorus saptanmasi), erken sepsis, IVK (intraventriküler kanama) [14] değerlendirildi. Pulmoner kanaması olan olgularda son surfaktan verilme zamanı, pulmoner kanama zamanı, son surfaktan uygulaması ile pulmoner kanama arasında geçen süre değerlendirildi. Çalışmada elde edilen verilerin değerlendirilmesinde istatistiksel analiz için SPSS (Statistical Package for Social Sciences) paket program1, 20 versiyonu kullanıldı. Grupların karşılaştırıldığı analizlerde kategorik değișkenler için $\mathrm{Ki}-$ kare test, iki grup ortalama karşılaştırmalarında Student- $t$ test kullanıldı. Sonuçlar \%95 güven aralığında, anlamlılık $\mathrm{p}<0,05$ düzeyinde kabul edilerek değerlendirildi.

\section{BULGULAR}

Pulmoner kanama sıklığ 28 . gestasyonel hafta altındaki prematürelerde \%13,7 (37/270) idi. Pulmoner kanaması olan prematürelerin \%83,7'si (31/37) kaybedilmiş idi. Pulmoner kanaması olan 37 prematüre ile kontrol grubunu oluşturan 233 prematüre olgu arasında erkek cinsiyet, düşük Apgar, çoğul gebelik, annede diyabet, sezaryen ile doğum, bozulmuş doppler bulguları, erken membran rüptürü, korioamnionit, oligohidroamnioz, preeklampsi, antenaral steroid sıklığı açısından istatistiksel farklılık yok idi (Tablo-1).

\begin{tabular}{|c|c|c|c|}
\hline & $\begin{array}{c}\text { Pulmoner } \\
\text { kanama } \\
(+) n=37\end{array}$ & $\begin{array}{c}\text { Kontrol } \\
n=233\end{array}$ & $p$ \\
\hline Doğum haftası & $24,9 \pm 1,7$ & $25,0 \pm 1,9$ & 0,66 \\
\hline Doğum ağırlığı & $696,6 \pm 141$ & $704,1 \pm 168,1$ & 0,79 \\
\hline Erkek cinsiyet & $15(\% 40)$ & $128(54,9)$ & 0,1 \\
\hline 5. Dk Apgar $\leq 7$ & $15(\% 40)$ & $98(\% 42,0)$ & 0,86 \\
\hline Çoğul gebelik & $6(\% 16,2)$ & $35(\% 15)$ & 0,85 \\
\hline Sezaryen & $20(\% 54)$ & $137(\% 58,7)$ & 0,58 \\
\hline $\begin{array}{l}\text { Patolojik Antenatal } \\
\text { Doopler Ultrason }\end{array}$ & $2(\% 5)$ & $21(\% 9)$ & 0,46 \\
\hline Erken membran rüptürü & $8(\% 21,6)$ & $54(\% 23)$ & 0,83 \\
\hline Korioamnionit & $1(\% 2,7)$ & $26(\% 11,1)$ & 0,11 \\
\hline Oligohidroamnioz & $5(\% 13,5)$ & $21(\% 9)$ & 0,38 \\
\hline Preeklempsi & $9(\% 24,3)$ & $44(\% 18,8)$ & 0,43 \\
\hline Antenatal steroid & $18(\% 48,6)$ & $134(\% 57,5)$ & 0,31 \\
\hline
\end{tabular}


Tablo 2. Pulmoner kanaması olan ve kontrol prematürelerde postnatal risk faktörleri

\begin{tabular}{|l|r|r|c|}
\hline & $\begin{array}{c}\text { Pulmoner } \\
\text { kanama } \\
(+) \mathrm{n=37}\end{array}$ & $\begin{array}{c}\text { Kontrol } \\
n=233\end{array}$ & $\mathrm{P}$ \\
\hline Patent duktus arteriorus & $22(\% 59,4)$ & $112(\% 48,4)$ & 0,19 \\
\hline Sepsis & $7(\% 18,9)$ & $48(\% 20,6)$ & 0,81 \\
\hline Respiratuar distres sendromu & $37(\% 100)$ & $202(\% 86,6)$ & 0,01 \\
\hline Surfaktan sıklı̆̆ı & $37(\% 100)$ & $202(\% 86,6)$ & 0,01 \\
\hline Pulmoner Hipertansiyon & $13(\% 35,1)$ & $51(\% 21,8)$ & 0,07 \\
\hline Intraventriküler kanama & $19(\% 51,3)$ & $98(\% 42)$ & 0,28 \\
\hline Ölüm & $31(\% 83,7)$ & $133(\% 57,0)$ & 0,002 \\
\hline
\end{tabular}

Postnatal bulgular değerlendirildiğinde pulmoner kanama öncesinde PDA, erken sepsis, pulmoner hipertansiyon ve IVK pulmoner kanaması olan prematüreler ile pulmoner kanamasi olmayan prematürlerde benzer siklıkta, RDS ve surfaktan verilme siklığ 1 pulmoner kanama olan prematürelerde pulmoner kanama olmayan prematürelere göre istatiksel olarak yüksek siklıkta saptand1 (Tablo-2). Pulmoner kanaması olan prematürelerde en son surfaktan verilme zamanı 19,1 $\pm 23,1$ saat, pulmoner kanama zaman $188 \pm 117$ saat, en son surfaktan verilme ile pulmoner kanama zamanı arasinda geçen süre $69,6 \pm 120,5$ saat idi. Pulmoner kanama gelișen prematürelerin 12 'sine $(\% 32,4)$ intratrakeal adrenalin uygulanmış, 10'u (\%27) HFO'ya alınmış, RDS gelişen 20 (\%54) prematüreye surfaktan uygulanmış idi.

\section{TARTIȘMA}

Prematüre yenidoğanların en önemli mortalite nedenlerinden biri olan pulmoner kanama ve risk faktörlerini değerlendiren çalıșma sayısı az ve çoğunluğu 2000 yılı öncesine aittir. Pulmoner kanama ile ilişkili risk faktörlerini değerlendiren Türkiye'de son yıllarda yapılan bir başka çalıșma yoktur. Bu çalışmada yenidoğan yoğun bakım servisimize yatan 28 hafta altındaki prematürelerde pulmoner kanama sıklığ 1 $\% 13,5$ bulunmuştur. 28 gestasyonel hafta altındaki prematürelerde pulmoner kanama risk faktörlerinin pulmoner kanama öncesinde RDS ve surfaktan uygulaması olduğu saptanmıștır. Pulmoner kanamadaki mortalite \%83,7 bulunmuştur. Antenatal bulgulardan antenatal steroidin fetal pulmoner damarlarda yapısal değişiklik yaratarak ve surfaktan yapımını arttırarak pulmoner kanama riskini azalttığı bir çalışma ile gösterilmiștir [15]. Ferrreira ve arkadaşlarının yaptığı çalışmada pulmoner kanama ile antenatal steroid arasında ilișki saptanmamıștır [16]. Bizim çalışmamızda pulmoner kanaması olan prematüreler ile kontrol grubu arasında antenatal steroid uygulama siklığı açısından faklılık bulunmamıştır. Doğum odasındaki entübasyon ile alveoler distansiyon ve alveoler kapiller damarlarda yaralanma ile pulmoner ka- nama riskinin arttığı daha önceki bir çalışmada gösterilmiştir [15]. Olgu kontrollü çalıșmalarda doğum odasında entübasyon veya düşük apgar ile pulmoner kanama arasındaki ilişki gösterilememiş̧ir $[4,16]$. Bizim çalışmamızda da düşük Apgar skoru ile pulmoner kanama arasında ilişki saptanmamıştır. Korioamnionitin akciğer olgunlaşmasını arttırarak prematürelerde RDS ve pulmoner kanamayı azalttığı bir çalışma ile gösterilmiştir [1]. Ferreira ve arkadaşlarının çalışmasında korioamnionitin pulmoner kanama riskini azalttığ 1 ya da arttırdığ [16]. Bizim çalışmamızda korioamnionit ile pulmoner kanama arasında ilişki saptanmamıştır. Postnatal pulmoner kanama risk faktörlerinden PDA ile ilgili Evans ve arkadaşlarının yaptığı çalışmada pulmoner kanaması olan prematürelerde PDA sıklığının daha yüksek olduğu saptanmıştır [7]. Scholl ve arkadaşlarının yaptığ1 çalışmada RDS'nin iyileşmesi ile azalan pulmoner rezistans ve erken ekstubasyon ile orta geniş PDA'dan sol sağ şantın artarak pulmoner kanamanın arttığ gösterilmiştir [17]. Bununla birlikte olgu kontrollü diğer çalışmalarda [15, 18] ve bizim çalışmamızda da pulmoner kanama ile PDA arasındaki ilişki gösterilememiştir. Bizim çalışmamızda pulmoner kanaması olan prematürelerde pulmoner kanama öncesi RDS ve surfaktan verilme sıklığı kontrol prematürelere göre daha yüksek saptandı. Surfaktan ile pulmoner kanamanın arttığını gösteren çalışmalar 2000 yılından önce yapılmıştır. Surfaktanın akciğer kompliansını iyileștirdiği, duktus arteriorusdan soldan sağa şantı arttırarak pulmoner kanama riskini arttırdığı [19], in vitro surfaktanın alveol kapillerine sitotoksik etkili olduğu gösterilmiştir [20]. Surfaktanın pulmoner kanamayı arttırıp arttırmadığını değerlendiren 2000 yılından sonra yapilan metaanalizde surfaktan verilen ve pulmoner kanaması olan bebeklerin intrauterin büyüme kısitlılığ 1 , solunumsal hastalık, PDA gibi pulmoner kanama için diğer risk faktörlerine sahip bebekler olduğu saptanmıştır. Yapılan çalışmaların randominize olmadığ 1 ve randominize kontrollü çalışmalara ihtiyaç oldu$\breve{g u}$ bildirilmiştir [21]. Son yıllarda yapılan bir çalışmada ise in vitro surfaktanın trombosit agregasyon ve adezyonunu azaltarak, pıhtılaşma zamanını uzatarak pulmoner kanamaya neden olabileceği gösterilmiştir [22].

Bu çalıșmada pulmoner kanaması olan çok düşük doğum ağırlıklı prematürelerde pulmoner kanamas1 olmayan prematürelere göre RDS ve surfaktan verilme siklığının yüksek olduğu gösterilmiştir. Bu çalışmada artan pulmoner kanama riskinden, RDS'nin mi yoksa surfaktan tedavisinin mi sorumlu olduğu ortaya konulmamıştır. Pulmoner kanama risk faktörlerini ve tedavi seçeneklerini değerlendiren çalışmalara ihtiyaç vardır. 


\section{KAYNAKLAR}

1- Pandit PB, O’Brien K, Asztalos E, Colucci E, Dunn MS. Out-come following pulmonary haemorrhage in very low birth weight neonates treated with surfactant. Arch Dis Child Fetal Neonatal Ed. 1999;81(1): 40-4.

2. Raju TN, Langenberg P. Pulmonary hemorrhage and exoge-nous surfactant therapy: a metaanalysis. J Pediatr. 1993;123(4):603-10.

3. Braun KR, Davidson KM, Henry M, Nielsen HC. Severe pulmonary hemorrhage in the premature newborn infant:analysis of presurfactant and surfactant eras. Biol Neonate.1999;75 (1) :18-30

4. Tomaszewska M, Stork E, Minich NM, Friedman H, Berlin S,Hack M. Pulmonary hemorrhage: clinical course and outcomes among very low-birth-weight infants. Arch Pediatr Adolesc Med.1999;153 (7):715-21.

5. Zahr RA, Ashfag A, Marron-Corwin M. Neonatal pulmonary hemorrhage. NeoReviews. 2012;13 (5): 302-06.

6. Papworth S, Cartlidge P.H.T. Pulmonary haemorrhage. Paediatrics. And Child Health. 2001;1 (3): 167-71.

7. Kluckow M, Evans N. Ductal shunting, high pulmonary blood flow, and pulmonary hemorrhage. J Pediatr 2000;137(1): 68-72.

8. Finlay ER, Subhedar NV. Pulmonary haemorrhage in preterm infants. Eur J Pediatr 2000;159(11):870-71.

9. Yen TA, Wang CC, Hsieh WS, Chou HC, Chen CY, Tsao PN. Short-term outcome of pulmonary hemorrhage in very-low-birth-weight preterm infants. Pediatrics and Neonatology. 2013;54(5):330-34.

10. Findlay RD, Taeusch HW, David- Cu R, Walther FJ. Lysis of red blood cells and alveolar epithelial toxicity by therapeutic pulmonary surfactants. Pediatr Res 1995;37(1): 26-30.

11. Dufourq N, Thomson M, Adhikari M, Moodley J. Massive pulmonary haemorrhage as a cause of death in the neonate a retrospective review. S Afr Med J 2004;94(4): 299-302.
12. Lin TW, Su BH, Lin HC, Hu PS, Peng CT, Tsai CH, et al. Risk factors of pulmonary hemorrhage in very-lowbirth-weight infants: a two-year retrospective study. Acta Paediatr Taiwan 2000;41(5): 255-58.

13. Pandit PB, Dunn MS, Colucci EA. Surfactant therapy in neonates with respiratory deterioration due to pulmonary hemorrhage. Pediatrics 1995;95(1): 32-36.

14. Pandit PB, Dunn MS, Kelly EN, Perlman M. Surfactant replacement in neonates with early chronic lung disease. Pediatrics 1995;95(6): 851-54.

15. Berger TM, Allred EN, Van Marter LJ. Antecedents of clinically significant pulmonary hemorrhage among newborn infants. J. Perinatol.2000;20(5): 295-300.

16. Ferreira CH, Carmona F, Martinez FE. Prevelance, risk factors and outcomes associated with pulmonary hemorrhafe in newborns. Jornal de Pediatria 2014;90(3): 316-22.

17. Scholl JE, Yanowitz TD. Pulmonary Hemorrhage in Very Low Birth Weight Infants:A Case-Control Analysis. J Pediatr. 2015; 166(4): 1083-4.

18. Bhandari V, Gagnon C, Rosenkrantz T, Hussain N. Pulmonary hemorrhage in neonates of early and late gestation. J. Perinat Med. 1999; 27(5):369-75.

19. Raju TN, Langenberg P. Pulmonary hemorrhage and exogenous surfactant therapy: a metanalysis. J.Peditr 1993; 123 (4):603-10.

20. Findlay RD, Taeusch HW, David- Cu R, Walther FJ. Lysis of red blood cells and alveolar epithelial toxicity by therapeutic pulmonary surfactants. Pediatr Res 1995;37(1): 26-30.

21. Aziz A, Ohisson A. Surfactant for pulmonary hemorrhage in neonates. Cochrane Database Syst Rev 2012;11;7:CD005254.

22. Strauss T, Rozenzweig N, Rosenberg N, Shenkman B, Livnat T, Morag I, Fruchtman Y, Martinowitz U, Kenet G. Surfactant impairs coagulation in-vitro: a risk factor for pulmonary hemorrhage? Thromb Res. 2013;132(5):599603. 